\title{
Structure and electrical properties of $\mathrm{Nb}-\mathrm{Ge}-\mathrm{C}$ nanocomposite coatings
}

\author{
Olof Tengstrand, Nils Nedfors, Lars Fast, Axel Flink, Ulf Jansson, Per Eklund and Lars \\ Hultman
}

\section{Linköping University Post Print}

\section{Tweet}

N.B.: When citing this work, cite the original article.

Original Publication:

Olof Tengstrand, Nils Nedfors, Lars Fast, Axel Flink, Ulf Jansson, Per Eklund and Lars Hultman, Structure and electrical properties of Nb-Ge-C nanocomposite coatings, 2014, Journal of Vacuum Science \&amp; Technology. A. Vacuum, Surfaces, and Films, (32), 4, 041509. http://dx.doi.org/10.1116/1.4882856

Copyright: American Vacuum Society http://www.avs.org/

Postprint available at: Linköping University Electronic Press http://urn.kb.se/resolve?urn=urn:nbn:se:liu:diva-109236 


\section{Structure and electrical properties of Nb-Ge-C nanocomposite coatings}

Running title: Structure and electrical properties of Nb-Ge-C nanocomposites

Running Authors: Tengstrand et al.

\section{Olof Tengstranda)}

Thin Film Physics Division, Department of Physics, Chemistry and Biology (IFM), Linköping University, SE-581 83 Linköping, Sweden

Nils Nedfors

Department of Chemistry, The Ångström Laboratory, Uppsala University, P.O. Box 538, SE-751 21 Uppsala, Sweden

\section{Lars Fast}

SP Technical Research Institute of Sweden, Box 857, SE-501 15 Borås, Sweden

\section{Axel Flink}

Thin Film Physics Division, Department of Physics, Chemistry and Biology (IFM), Linköping University, SE-581 83 Linköping, Sweden

Impact Coatings AB, Westmansgatan 29, SE-582 16 Linköping, Sweden

Ulf Jansson ${ }^{\text {b) }}$

Department of Chemistry, The Ångström Laboratory, Uppsala University, P.O. Box 538, SE-751 21 Uppsala, Sweden

\section{Per Eklund ${ }^{\text {b) }}$}

Thin Film Physics Division, Department of Physics, Chemistry and Biology (IFM), Linköping University, SE-581 83 Linköping, Sweden

\section{Lars Hultman ${ }^{\text {b) }}$}

Thin Film Physics Division, Department of Physics, Chemistry and Biology (IFM), Linköping University, SE-581 83 Linköping, Sweden

a)Electronic mail: olote@ifm.liu.se

b)American Vacuum Society member. 
Nb-Ge-C nanocomposite thin films were deposited by dc magnetron sputtering using three elemental targets. The films consist of substoichiometric $\mathrm{NbC}_{\mathrm{x}}$ in a nm-thick matrix of amorphous C and Ge. Films with no Ge contain grains that are elongated in the growth direction with a (111) preferred crystallographic orientation. With the addition of 12 at.\% Ge, the grains are more equiaxed and exhibit a more random orientation. At even higher Ge contents, the structure also becomes denser. The porous structure of the low Ge content films result in $\mathrm{O}$ uptake from the ambient. With higher $\mathrm{C}$ content in the films both the amount of amorphous $\mathrm{C}$ and $\mathrm{C} / \mathrm{Nb}$-ratio increases. The contact resistance was measured by four-point technique as a function of contact force between $0-10 \mathrm{~N}$. The lowest contact resistance $(1.7 \mathrm{~m} \Omega)$ is obtained at $10 \mathrm{~N}$. The resistivity varies between $470-1700 \mu \Omega \cdot \mathrm{cm}$ depending on porosity and $\mathrm{O}$ content. 


\section{INTRODUCTION}

Binary and ternary ceramic materials are interesting because of the opportunities to tailor their properties. For example, several different transition-metal-carbide-based materials systems have already been studied because of their good tribological ${ }^{1,2}$ and electrical properties ${ }^{3,4}$. Among them are Nb-C composites, which recently were reported to be promising both as electrical contact materials ${ }^{5}$ and as protective coatings ${ }^{6}$. The binary transition-metal-carbide composites often consist of nano-crystalline metal-carbide grains embedded in an amorphous carbon matrix (nc-MeC/a-C). The properties of the films have been shown to depend on both the grain size and the amount of amorphous carbon matrix. Addition of a third element enhances the ability to tailor the material. The added element can be a weak carbide former such as Al, Fe or $\mathrm{Cu}$, where the formation of metastable solid solutions of the $\mathrm{MeC}$ can be used to control the amount of carbon phase ${ }^{7}$. Another example of a widely used additive is $\mathrm{Si}$, which reacts with $\mathrm{C}$ to form an amorphous $\mathrm{SiC}$ matrix and reduces the grain size of the MeC grains ${ }^{8,9}$ or, at high $\mathrm{Si}$ contents, leads to an amorphous material ${ }^{10-15}$. Also the addition of Ge can yield a reduced grain size ${ }^{16}$ or the formation of an amorphous material ${ }^{17}$. Of particular interest for electrical contact applications is that the addition of Ge can give a reduction in resistivity ${ }^{17}$ and a lower contact resistance compared to the inclusion of $\mathrm{Si}^{16}$.

The result from the Nb-C system ${ }^{5,18}$ and the results from addition of $\mathrm{Ge}^{16,17}$ to the Ti-C and V-C systems suggest that the Nb-Ge-C system could have potential as electrical-contact material. This ternary system is less studied. Known phases are marked with filled circles in Fig. 1. No stable GeC phase is known and the mutual solubility of Ge and C is negligible ${ }^{19}$. The NbC system has been reviewed by, for example, Storms ${ }^{20}$ and Toth ${ }^{21}$. The system has a hexagonal $\mathrm{Nb}_{2} \mathrm{C}$ phase and one cubic $\mathrm{NbC}_{\mathrm{x}}$ phase with a large stability range that can be 
understoichiometric within $0.7<x<1.0$. In the Nb-Ge system several phases exist ${ }^{22}$. Some of them, including the well-studied $\mathrm{Nb}_{3} \mathrm{Ge}$ with an A15 structure, have superconducting properties. Additional elements, such as $\mathrm{C}$ and $\mathrm{N}$, can stabilize NbGe structures ${ }^{23,24}$. Investigating phase equilibria in the Nb-Ge-C system, Spear and Palino discovered $\mathrm{Nb}_{3} \mathrm{GeC}^{25}$. Recently, we used a theoretical optimization method to calculate the stability of hypothetical phases in the ternary system ${ }^{26}$. A stable $\mathrm{Nb}_{2} \mathrm{GeC}$ phase was predicted by this approach and synthesized using magnetron sputtering ${ }^{26}$.

In the present study, we investigate $\mathrm{Nb}-\mathrm{Ge}-\mathrm{C}$ as a nanocomposite material. Materials consisting of different phases can be designed by magnetron sputtering at thermal nonequilibrium conditions. The low temperature at which magnetron sputtering can be performed is also required for deposition onto industrially relevant substrates, such as $\mathrm{Cu}$, which tend to soften at elevated temperatures ${ }^{27}$. Thus, we use dc magnetron sputtering for the deposition of Nb-Ge-C thin films at a substrate temperature of $200^{\circ} \mathrm{C}$. A matrix consisting of 12 different compositions was set up in order to explore the effects of varying the $C$ and Ge content. Three types of substrates were used. Si(001) and oxidized Si substrates were used for structural characterization and for resistivity measurements of the samples, respectively. Films on Ni-electroplated CuSn6 (Cu alloyed with 6 wt\% Sn) substrates were studied with respect to electrical contact resistance.

\section{EXPERIMENTAL DETAILS}

Nb-Ge-C thin films were deposited from elemental targets using dc magnetron sputtering in an Ar discharge with an Ar pressure of 4 mTorr (0.53 Pa). The Ge target (Ø50 mm) was facing the substrates, and the $\mathrm{Nb}$ and $\mathrm{C}$ targets (both $\varnothing 75 \mathrm{~mm}$ ) were positioned at angles of $35^{\circ}$ to the substrate normal. The target-to-substrate distances were $180 \mathrm{~mm}$ for the $\mathrm{Nb}$ and $\mathrm{C}$ and $155 \mathrm{~mm}$ for the Ge target. During depositions, the substrate holder was rotated at $30 \mathrm{rpm}$ to obtain a 
uniform deposition flux distribution. A dc bias of $-50 \mathrm{~V}$ was applied to the substrates. The composition of the films was altered by changing the current of the $\mathrm{Nb}$ magnetron and the Ge magnetron, between 150 to $250 \mathrm{~mA}$ and 0 to $60 \mathrm{~mA}$, respectively. The current to the $\mathrm{C}$ magnetron was kept constant at $400 \mathrm{~mA}$ during all depositions. This resulted in the three different series illustrated in Fig. 1. In contrast to the marked known phases in Fig. 1, the position of the marker for the three series should only be seen as the overall composition.

Single-crystal Si(001) wafer substrates were used for structural characterization and compositional analysis of the samples. Electrical resistivity was measured for films deposited on oxidized Si substrates. Ni-electroplated CuSn6 substrates were used for the electrical contact resistance measurements.

Since Cu tends to soften at temperatures above $200{ }^{\circ} \mathrm{C}^{27}$, the substrates were kept at $200{ }^{\circ} \mathrm{C}$ during the depositions. Prior to deposition, the Si substrates were cleaned with acetone and isopropanol in an ultrasonic bath. The Ni-electroplated CuSn6 substrates were cleaned in neutracon (5\%) and isopropanol in an ultrasonic bath. The substrates were blown dry in $\mathrm{N}_{2}$ before being introduced into the chamber.

X-ray diffraction (XRD) and X-ray reflectivity (XRR) data were acquired from $\theta-2 \theta$ measurements using $\mathrm{Cu} \mathrm{K} \alpha$ radiation. XRD was used for determining the texture and crystalline components of the films. The XRD peak broadening was used to estimate the grain size using the Scherrer equation. XRR data were used for measuring the density of the samples by fitting the data with simulated XRR curves using the X'Pert Reflectivity v1.3 software from Panalytical.

A LEO 1550 scanning electron microscope (SEM) operated at an acceleration voltage of 5 $\mathrm{kV}$ was used to obtain both cross-sectional and plan-view images of the samples. Transmission electron microscopy (TEM) cross-section samples were prepared by mechanical polishing down to $\sim 50 \mu \mathrm{m}$ followed by ion milling in a Gatan precision ion polishing system (PIPS) using $5 \mathrm{keV}$ 
$\mathrm{Ar}^{+}$ions with a final polishing step with $2 \mathrm{keV} \mathrm{Ar}^{+}$ions for 10 min. TEM images and diffraction patterns were obtained using a FEI Tecnai G2 TF 20 UT with a field-emission gun operated at an acceleration voltage of $200 \mathrm{kV}$. The microscope was also used in scanning TEM (STEM) mode together with energy dispersive X-ray spectroscopy (EDX) in order to obtain elemental mapping from a 31 x $31 \mathrm{~nm}^{2}$ large area with pixel size of 1 x $1 \mathrm{~nm}^{2}$.

The elemental composition of the coatings was determined from X-ray photoelectron spectroscopy (XPS) depth profiles using a Physical Systems Quantum 2000 spectrometer with monochromatic Al Ka radiation. Sensitivity factors were determined from a subset of the films for which the composition was also determined with elastic recoil detection analysis. The depth profiles were acquired by rastered $\mathrm{Ar}^{+}$-ion sputtering over an area of 1 x $1 \mathrm{~mm}^{2}$ with ions having energy of $200 \mathrm{eV}$. High resolution spectra used for chemical analysis were acquired after $200 \mathrm{eV}$ $\mathrm{Ar}^{+}$-ion sputtering for $30 \mathrm{~min}$. The XPS analysis area was set to a diameter of $200 \mu \mathrm{m}$. Energy calibration was carried out with Au and Ag reference samples.

Contact resistance measurements were made in the range 1-10 $\mathrm{N}$ using a central Au ball electrode with a diameter of $4.42 \mathrm{~mm}$ in a four-terminal measurement. A more detailed description of the setup can be found in Lauridsen et al. ${ }^{28}$. The error was estimated as the standard deviation by measuring at least 5 different positions on the sample. A four-point probe was used to measure the sheet resistance with a correction factor of 0.9822 due to the finite size of the sample ${ }^{29}$.The electrical resistivity was calculated by multiplying the measured sheet resistance from a four-point probe by the thickness as measured from cross-sectional SEM.

Hardness measurements were performed using a Hysitron TI-950 Tribo-Indenter equipped with a Berkovich $142.3^{\circ}$ diamond probe, calibrated using a fused silica standard. For each sample, a minimum of 25 indents were made at an indentation depth of $55 \mathrm{~nm}$, corresponding to a maximum applied load of $1.25 \mathrm{mN}$. The indentation procedure consisted of 
three steps: 1) loading to $\mathrm{P}_{\max }$ during $5 \mathrm{~s}$, 2) hold for $2 \mathrm{~s}$, and 3) unloading during 5 s. For measurement of experimental error, the standard deviation is used.

\section{RESULTS AND DISCUSSION}

\section{A. Microstructure and chemical bonding}

Figure 2 shows $\theta$-2 $\theta$ X-ray diffractograms for the different Nb-Ge-C samples. The only observed crystalline phase is $\mathrm{NbC}$ in the $\mathrm{B} 1(\mathrm{NaCl})$ structure. For the pure $\mathrm{NbC}$ films, the lattice parameter ranges from 4.47-4.46 $\AA$, which is in good agreement with the reference value of 4.46 $\AA$ (ICDD, PDF card 65-7964). For the binary NbC films, the scans show the preferred crystallographic orientation [111] along the substrate normal. This texture is more pronounced with a higher $\mathrm{Nb}$ content.

With addition of 12 at.\% Ge, the intensity of the NbC 111 peak decreases in proportion to other peaks, showing loss of texture in the films. Peak broadening is also seen, corresponding to a reduction in grain size. For further addition of Ge, the peak intensity decreases even more and additional peak broadening can be seen. For the film with highest Ge and C content, no distinguishable peaks can be seen. Thus, the structure can be said to be X-ray amorphous. The reduction of grain size with addition of Ge is also observed in other carbide systems, e.g. V-Ge-C

and Ti-Ge-C-Ag ${ }^{16,17}$. Using the Scherrer equation gives an estimation of the grain size in the films. With the addition of Ge the grain size drops from 10-20 nm for the binary films to between 4-8 $\mathrm{nm}$ in all the ternary films.

The XPS spectra are qualitatively similar for all different deposition series. Representative examples of the C1s spectrum for films from S1 are shown in Fig. 3(a). The spectrum for the pure NbC film shows two distinct peaks. The first peak at $282.7 \mathrm{eV}$ can be assigned to $\mathrm{C}$ bonded 
to $\mathrm{Nb}(\mathrm{C}-\mathrm{Nb})^{5}$, and the second peak at $284.6 \mathrm{eV}$ corresponds to $\mathrm{C}$ bonded to $\mathrm{C}(\mathrm{C}-\mathrm{C})$ in an amorphous phase ${ }^{30}$. When Ge is added, the amount of C-C bonds is decreased and a contribution from C bonded to Ge (C-Ge) is seen between $283.7-283.9 \mathrm{eV}$ depending on $\mathrm{Ge}$ content ${ }^{16,31}$.

Using compositional information for $\mathrm{C}$ and $\mathrm{Nb}$ together with the relative amount of $\mathrm{C}-\mathrm{Nb}$ bonds seen in $\mathrm{C} 1 \mathrm{~s}$, the stoichiometry of the $\mathrm{NbC}_{\mathrm{x}}$ grains was calculated. The results show that the $\mathrm{NbC}_{\mathrm{x}}$ grains in the binary films are substoichiometric with $0.65<\mathrm{x}<0.80$ with the highest $\mathrm{C}$ content for the films with the highest $\mathrm{C} / \mathrm{Nb}$ ratio. In all series $\mathrm{x}$ is increased with the addition of Ge and is between 1.1-1.2 times higher than $\mathrm{x}$ in the corresponding films without Ge.

Ge has very low solubility in transition metal carbides ${ }^{32}$ and it is therefore likely to segregate out of the $\mathrm{NbC}_{\mathrm{x}}$ grains during deposition. This was shown by Lauridsen et al. ${ }^{16}$ for TiGe-C-Ag films deposited at $300^{\circ} \mathrm{C}$, where Ge formed elemental crystallites (diameter $\sim 10 \mathrm{~nm}$ ) that could be observed in XRD and by EDX mapping. In the present study, we observe no peaks belonging to crystalline Ge in the XRD. However, it is clear from the Ge2p spectra in Fig. 3(b) that also in this study most of the Ge is bonded to Ge (the peak located at $1217.2 \mathrm{eV})^{16,30}$. In addition, a contribution from Ge-C can be seen at $\sim 1219 \mathrm{eV}$. It can therefore be assumed that the lower deposition temperature in this study $\left(200^{\circ} \mathrm{C}\right)$ compared to Lauridsen et al. $\left(300^{\circ} \mathrm{C}\right)$ is low enough to hinder complete segregation of $\mathrm{C}$ from the GeC-matrix. Moreover, Li et al. ${ }^{33}$ found that an amorphous phase was formed when 3 at.\% of $\mathrm{C}$ was dissolved into Ge at deposition temperatures below $500{ }^{\circ} \mathrm{C}$. Thus, the remaining $\mathrm{C}$ in the $\mathrm{Ge}(\mathrm{C})$-matrix in combination with the low deposition temperature yields an amorphous $\mathrm{Ge}(\mathrm{C})$-phase.

In addition to the Ge-Ge and Ge-C peaks, a tail of the Ge-Ge peak towards lower energies can be seen in Fig. 3(b). Comparing the electronegativity for the different element indicates that this tail comes from Ge binding to Nb. The Nb-Ge bonds were confirmed in Nb3d spectra (not shown) as a shift of the $\mathrm{Nb}-\mathrm{C}$ peaks towards lower bond energies. 
As presented in Fig. 4(a), the results from XPS depth-profiles also show high amount of O contamination (up to 20 at.\%) throughout the films. In each series, the oxygen content follows the same trend with the maximum O content at the lowest Ge contents. Due to good vacuum conditions (base pressure $10^{-7}-10^{-6} \mathrm{~Pa}$ ) it is not likely that oxygen is incorporated during the deposition process. While XRR measurements give the density of the films, a direct comparison between the oxygen content and the densities will not give relevant results since the composition differs between the samples. Instead, the density was calculated assuming NbC grains in an amorphous matrix of $\mathrm{C}$ and Ge with the proportion of each component calculated from XPS data. The ratio between the calculated and measured density gives an indication of the porosity of the material, as shown in Fig. 4(b). It can be seen that the density-to-O-content ratio has a linear relationship. With higher porosity, the $\mathrm{O}$ content increases. A porous structure where the $\mathrm{O}$ has reacted with the films when exposed to air is therefore probable. In order to reduce the $\mathrm{O}$ contamination, denser films would therefore be desirable. In this study this is achieved for the high Ge content (above 20 at.\%) but also deposition conditions, such as bias, pressure and deposition temperature, play an important role ${ }^{34}$. For example, about half the oxygen content was found for a binary Nb-C composite film with the same C content as the S1 film, but deposited at 3 mTorr and $300{ }^{\circ} \mathrm{C}$ (compared to 4 mTorr and $200{ }^{\circ} \mathrm{C}$ used here) ${ }^{5}$. Thus, it should be possible to reduce the total $\mathrm{O}$ content significantly in all films by further investigations of the deposition parameters.

Figure 5 shows plan-view and cross-sectional SEM images for four different samples. The binary NbC sample in series S1 can be seen in Fig. 5(a). The plan-view shows a rough surface while the cross-section shows a columnar and porous structure. At higher Ge content in S1 the columnar structure becomes gradually less pronounced and the surface roughness decrease. For the highest Ge content of 34 at.\% (Fig. 5(b)), no evident morphology is seen. This is not 
surprising, since Ge is a known glass-former ${ }^{17,35}$. For the NbC film with highest Nb content in series S3 (Fig. 5(c)), facetted grains form. Considering that the XRD result shows a preferred $<111>$ growth direction, these facets can be interpreted as the projected corners of a cube, which means that they correspond to $\mathrm{NbC}\{100\}$ planes. The facets disappear when $\sim 12$ at.\% Ge is added. With further increase in Ge content, the surface roughness decreases until it becomes as seen in Fig. 5(d), which shows the sample in S3 with highest Ge content (27 at.\%).

Figure 6 shows cross-sectional overview TEM images together with selected area electron diffraction (SAED) patterns and high resolution TEM image insets for some of the films. Figure 6(a) from the binary $\mathrm{Nb}-\mathrm{C}$ film in series S3 reveals a polycrystalline material consisting of $\mathrm{NbC}$ grains with a strongly preferred [111] orientation in the growth direction. The NbC grains are elongated in the growth direction and grow with a columnar structure. The columnar structure decreases with a lower Nb content as seen for the binary film in series S1 in Fig. 6(b). In this figure SAED also shows less texture of the NbC grains, although some intensity variation in the diffraction rings still indicates a texture. In Fig. 6(c), the S3 film containing 27 at.\% Ge is shown. The overview image reveals a smooth film and the SAED pattern shows a random orientation of the NbC grains. No crystalline Ge can be seen in SAED. The high resolution TEM image shows that the grains are equiaxed and have a diameter of $\sim 8 \mathrm{~nm}$. The grains are closely packed together with no visible matrix. Figure 6(d) shows the S1 film with a Ge content of 34 at.\%. The films are similar to (c), but the size of the NbC grains is smaller than $5 \mathrm{~nm}$.

Figure 7 shows STEM images of the structural evolution when adding Ge or $\mathrm{C}$ to the structure. For a low $\mathrm{C} / \mathrm{Nb}$ ratio without $\mathrm{Ge}$, a porous columnar structure is formed as shown in Fig. 7(a). If more $\mathrm{C}$ is added, as for the binary sample from series $\mathrm{S} 1$ shown in Fig. 7(b), a feather-like structure develops. This feather-like structure is also seen for the lower Ge contents in series S3 (not shown). At 34 at.\% Ge (series S3, Fig. 7(c)), the structure has become dense and 
there is no feather-like structure present. To obtain the distribution of Ge and $\mathrm{Nb}$, elemental maps from EDX were acquired for the sample with 14 at.\% Ge in series S1. The maps are presented in the insets in Fig. 7(d). In this figure also the mapped region has been marked. As indicated by the XPS results, Ge is mainly separated from the $\mathrm{Nb}$.

\section{B. Mechanical and electrical properties}

The hardness of the binary films is in the range 9.4 to 12.2 GPa with the highest hardness for the highest $\mathrm{C}$ content. These values are lower than previous reported for Nb-C thin films, which are typically between $12-25 \mathrm{GPa}^{5,6,36}$. All Ge-containing samples have almost the same hardness of $9.8 \pm 0.6 \mathrm{GPa}$.

The resistivity in transition metal carbide based thin films has been related to impurities, porosity, grain size, amount of transition metal, and thickness of the amorphous matrix 4, 13, 15, 37 . Also, the location of a given impurity has large effect on the resistivity ${ }^{38}$. In the analysis above it is seen that the present $\mathrm{Nb}-\mathrm{Ge}-\mathrm{C}$ thin films mainly have a porous columnar structure of nanosized MeC grains surrounded by an amorphous phase comprised of C, Ge, and O. Since no network of conducting $\mathrm{MeC}$ grains is seen in the in-plane direction (path of current in the measurement), it is reasonable to assume that the least conducting phase(s), i.e. oxygen-containing matrix or oxide, will have the largest influence on the resistivity. In Fig. 8, the resistivity is therefore plotted as a function of the $\mathrm{O}$ content. For higher $\mathrm{O}$ contents, an increase in the resistivity is seen, meaning that oxides in fact affect the resistivity. A tendency that a higher $\mathrm{C}$ content gives a higher resistivity for a given $\mathrm{O}$ content is also found, which is consistent with previous studies ${ }^{3,5}$. Porosity has also previously been used as explanation of high resistivity ${ }^{4}$, since that is a predominant route for the $\mathrm{O}$ uptake. In this study an increased Ge content therefore probably lowers the resistivity mainly due the formation of denser films. As shown in Fig. 8 the resistivity 
of the films changes between $470-1700 \mu \Omega \cdot \mathrm{cm}$. This can be compared to $210-3200 \mu \Omega \cdot \mathrm{cm}$ in the case of Nb-Si-C ${ }^{15}$ and $\sim 300 \mu \Omega \cdot \mathrm{cm}$ for Ti-Si-C ${ }^{39}$. The resistivities of the Nb-Ge-C films are thus in the same order of magnitude as the other nanocomposites, despite the high amount of $\mathrm{O}$ and porosity. However, the long-term usability will probably be affected by the high porosity.

Figure 9(a) shows the contact resistances for all the films against an Au probe at a contact force of $10 \mathrm{~N}$. The S3 film with highest Ge content is excluded from the comparison since its contact resistance values from repeated measurements did not converge towards a specific value. All other films yield significant values that range between 1.7 and $4.8 \mathrm{~m} \Omega$. These values are comparable to the $1.2 \mathrm{~m} \Omega$ measured for the Ag reference sample, which means that any surface oxides must to some extent have been penetrated at this contact force. To show this, a typical load and unload curve is illustrated with the film from S2 containing 21 at.\% Ge in Fig. 9(b). An Ag-reference film deposited on the same type of substrate is also included. For loading up to contact forces $<2 \mathrm{~N}$, the contact resistance rapidly decreases. This is expected for films where an increasing contact load breaks non-conducting surface oxides and deforms the contacting materials and thus creates larger contact spots. After this the contact resistance decreases more slowly until it reaches a minimum value at the highest applied force $(10 \mathrm{~N})$. The unloading curve follows the load curve down to $3 \mathrm{~N}$. At lower contact forces the increase in contact resistance is smaller for the unload curve compared to the loading curve, since surface oxides is already broken and the contacting material(s) has deformed.

The contact resistance in transition metal carbides is a complex property that depends on microstructure, hardness, and resistivity ${ }^{3-5}$. For the binary films, a higher amount of amorphous carbon and higher resistivity could be one reason for the higher observed contact resistance. The contact resistance also largely depends on the number and size of conducting contact areas (aspots) formed between the two contacting materials ${ }^{40}$. A smooth surface will make it more 
difficult to penetrate surface oxides and could thereby reduce the electrically conducting contact area. Since it is clear from XPS that we have oxides in the material, the reduced roughness of the films could explain why increased Ge content gives a higher contact resistance for the series S2 and S3 films. The behavior of decreasing contact resistance with increasing Ge content in the S1 films is, however, a more complex behavior. The addition of 13 at.\% Ge gives higher porosity and resistivity, and is therefore not expected to reduce the contact resistance. It should be noted that the error in measuring the contact resistance for the binary Nb-C film in series S1 is large and the decrease for adding Ge might not be as large as indicated.

\section{IV.CONCLUSIONS}

The Nb-Ge-C films have a nc-NbC $\mathrm{x} / \mathrm{a}-\mathrm{C}$ :Ge structure with $\mathrm{C} / \mathrm{Nb}$ ratio (x) between 0.65-0.80. Adding $\mathrm{Ge}$ to $\mathrm{NbC}$ results in grain refinement as well as a change in grain shape from grains elongated in the growth direction to equiaxed grains. A small addition of Ge gives a more porous structure, but with further increase in Ge content the films develop a less columnar and denser structure. The porosity allows $\mathrm{O}$ to diffuse into the film which leads to high amounts of incorporated $\mathrm{O}$. The electrical resistivity is affected by the porosity and the $\mathrm{O}$ content and increases with increased $\mathrm{O}$ content. However, the contact resistance is not largely affected by the porosity since it mainly depends on surface properties. The small increase of the contact resistance seen with increased Ge content is instead due to a smoother surface, which lowers the contact pressure and makes it harder to penetrate surface oxides. Although addition of Ge lowers the resistivity as an effect of densifying the films, the contact resistance does not improve by the

addition of Ge. The conclusion is thus that it is not beneficial to add Ge into Nb-C nanocomposite films considering the electrical contact properties. The problem with high porosity should instead 
be solved through the deposition conditions, e.g., by increasing the deposition temperature or the energetics of the deposition flux.

\section{Acknowledgements}

The authors acknowledge Jens Jensen at the Thin Film Physics Division, Linköping University for ERDA measurements and Hanna Fager at the Thin Film Physics Division, Linköping University for nanoindentation hardness measurements. The work was financially supported by Vinnova (Swedish Governmental Agency for Innovation Systems) through the VINN Excellence Centre FunMat. The Knut and Alice Wallenberg Foundation supported the electron microscopy laboratory at Linköping operated by the Thin Film Physics Division. O.T, U.J., and P.E. also acknowledge support from the Swedish Foundation for Strategic Research (SSF) through the Synergy Grant FUNCASE.

\section{References}

${ }^{1}$ A. A. Voevodin, S. V. Prasad and J. S. Zabinski, J. Appl. Phys. 82, 855 (1997).

${ }^{2}$ D. Nilsson, F. Svahn, U. Wiklund and S. Hogmark, Wear 254, 1084 (2003).

${ }^{3}$ E. Lewin, E. Olsson, B. André, T. Joelsson, Å Öberg, U. Wiklund, H. Ljungcrantz and U. Jansson, Plasma Processes Polym. 6, S928 (2009).

${ }^{4}$ P. Eklund, J. Emmerlich, H. Högberg, O. Wilhelmsson, P. Isberg, J. Birch, P. O. Å Persson, U. Jansson and L. Hultman, J. Vac. Sci. Technol., B 23, 2486 (2005).

${ }^{5}$ N. Nedfors, O. Tengstrand, E. Lewin, A. Furlan, P. Eklund, L. Hultman and U. Jansson, Surf. Coat. Technol. 206, 354 (2011). 
${ }^{6}$ R. A. Mesquita and C. A. Schuh, Surf. Coat. Technol. 207, 472 (2012).

${ }^{7}$ U. Jansson, E. Lewin, M. Råsander, O. Eriksson, B. André and U. Wiklund, Surf. Coat. Technol. 206, 583 (2011).

${ }^{8}$ C. Lopes, N. M. G. Parreira, S. Carvalho, A. Cavaleiro, J. P. Rivière, E. Le Bourhis and F. Vaz, Surf. Coat. Technol. 201, 7180 (2007).

${ }^{9}$ W. Gulbinski, T. Suszko, A. Gilewicz, B. Warcholinski and Z. Kuklinski, Surf. Coat. Technol. 200, 4179 (2006).

${ }^{10}$ M. Naka, H. Sakai, M. Maeda and H. Mori, Mater. Sci. Eng., A 226-228, 774 (1997).

${ }^{11}$ I. Bertóti, A. Tóth, M. Mohai and J. Szépvölgyi, Surf. Coat. Technol. 206, 630 (2011).

${ }^{12}$ J. L. Endrino and J. E. Krzanowski, J. Mater. Res. 17, 3163 (2002).

${ }^{13}$ M. Andersson, S. Urbonaite, E. Lewin and U. Jansson, Thin Solid Films 520, 6375 (2012).

${ }^{14}$ J. E. Krzanowski and J. Wormwood, Surf. Coat. Technol. 201, 2942 (2006).

${ }^{15}$ N. Nedfors, O. Tengstrand, A. Flink, P. Eklund, L. Hultman and U. Jansson, Thin Solid Films 545, 272 (2013).

${ }^{16}$ J. Lauridsen, P. Eklund, J. Jensen, A. Furlan, A. Flink, A. M. Andersson, U. Jansson and L. Hultman, Thin Solid Films 520, 5128 (2012).

${ }^{17}$ O. Wilhelmsson, P. Eklund, H. Högberg, L. Hultman and U. Jansson, Acta Mater. 56, 2563 (2008). 
${ }^{18}$ N. Nedfors, O. Tengstrand, A. Flink, A. M. Andersson, P. Eklund, L. Hultman and U. Jansson, Surf. Coat. Technol. 253, 100 (2014)

${ }^{19}$ M. Krishnamurthy, B. K Yang and W. H. Weber, Appl. Phys. Lett. 69, 2572 (1996).

${ }^{20}$ E. K. Storms, The refractory carbides, (Academic Press, New York, 1967),

${ }^{21}$ L. E. Toth, Transition Metal Carbides and Nitrides, (Academic Press, New York, 1971),

${ }^{22}$ J. L. Jorda, R. Flükiger and J. Müller, J. Less-Common Met. 62, 25 (1978).

${ }^{23}$ A. D. Bortolozo, C. A. M. Dos Santos, R. F. Jardim, C. Ritter, A. Devishvili, M. Rotter, F. G. Gandra and A. J. S. MacHado, J. Appl. Phys. 111, 123912 (2012).

${ }^{24}$ K. W. Richter, H. Flandorfer and H. Fritz Franzen, J. Alloys Compd. 320, 87 (2001).

${ }^{25}$ K. E. Spear and D. F. Palino, Mater. Res. Bull. 18, 549 (1983).

${ }^{26}$ P. Eklund, M. Dahlqvist, O. Tengstrand, L. Hultman, J. Lu, N. Nedfors, U. Jansson and J. Rosén, Phys. Rev. Lett. 109, 035502 (2012).

${ }^{27}$ M. Braunovic, Electrical contacts - fundamentals, applications and technology, (CRC Press, Boca Raton, 2006),

${ }^{28}$ J. Lauridsen, J. Lu, P. Eklund, L. Hultman, Å Öberg, M. Lindgren, L. Fast, E. Lewin and U. Jansson, Proc. 56th IEEE Holm Conference on Electrical Contacts, 288 (2010). 
${ }^{29}$ F. M. Smits, Bell Syst. Tech. J. 37, 711 (1958).

${ }^{30}$ J. F. Moulder, W. F. Stickle, P. E. Sobol and K. D. Bomben, Handbook of X-ray Photoelectron Spectroscopy, 3rd edn. (Physical Electronics, Inc, Eden Prairie, 1995),

${ }^{31}$ J. Vilcarromero and F. C. Marques, Appl. Phys. A 70, 581 (2000).

${ }^{32}$ U. Jansson and E. Lewin, Thin Solid Films 536, 1 (2013).

${ }^{33}$ W. Li, I. Shah, D. Guerin, J. G. Chen and H. Hwu, J. Vac. Sci. Technol., A 19, 2617 (2001).

${ }^{34}$ I. Petrov, P. B. Barna, L. Hultman and J. E. Greene, J. Vac. Sci. Technol., A 21, S117 (2003).

${ }^{35}$ S. Sharma, R. Vaidyanathan and C. Suryanarayana, Appl. Phys. Lett. 90, 111915 (2007).

${ }^{36}$ K. Zhang, M. Wen, Q. N. Meng, C. Q. Hu, X. Li, C. Liu and W. T. Zheng, Surf. Coat. Technol. 212, 185 (2012).

${ }^{37}$ J. Lauridsen, P. Eklund, T. Joelsson, H. Ljungcrantz, Å Öberg, E. Lewin, U. Jansson, M. Beckers, H. Högberg and L. Hultman, Surf. Coat. Technol. 205, 299 (2010).

${ }^{38}$ J. Emmerlich, P. Eklund, D. Rittrich, H. Högberg and L. Hultman, J. Mater. Res. 22, 2279 (2007).

${ }^{39}$ P. Eklund, Surf. Eng. 23, 406 (2007).

${ }^{40}$ R. Holm, Electric contacts : theory and application, (Springer-Verlag, Berlin, 1979). 


\section{Figures}

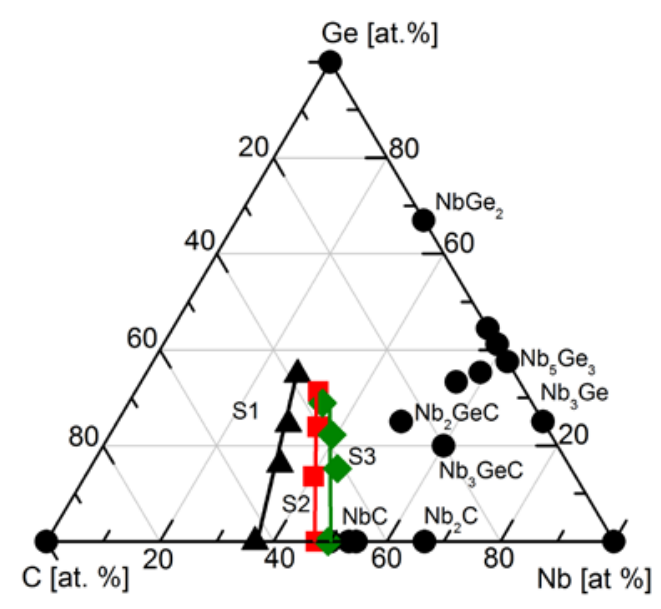

Figure 1. (Color online) Composition of deposited Nb-Ge-C films. The black circles represent known phases in the Nb-Ge-C system.

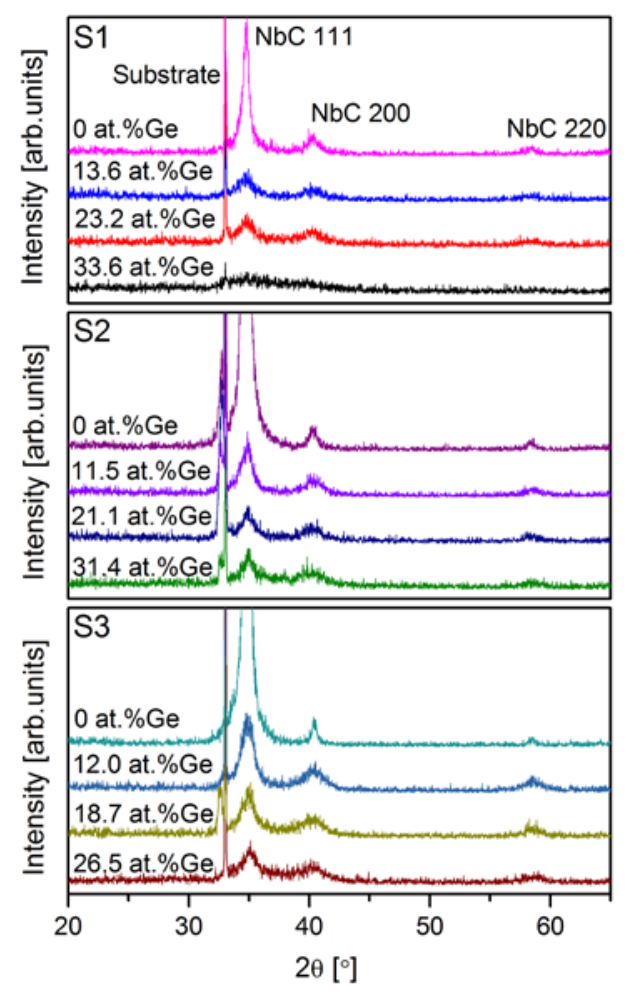

Figure 2. (Color online) $\theta-2 \theta$ X-ray diffractograms from all the studied films grown on Si substrates. 

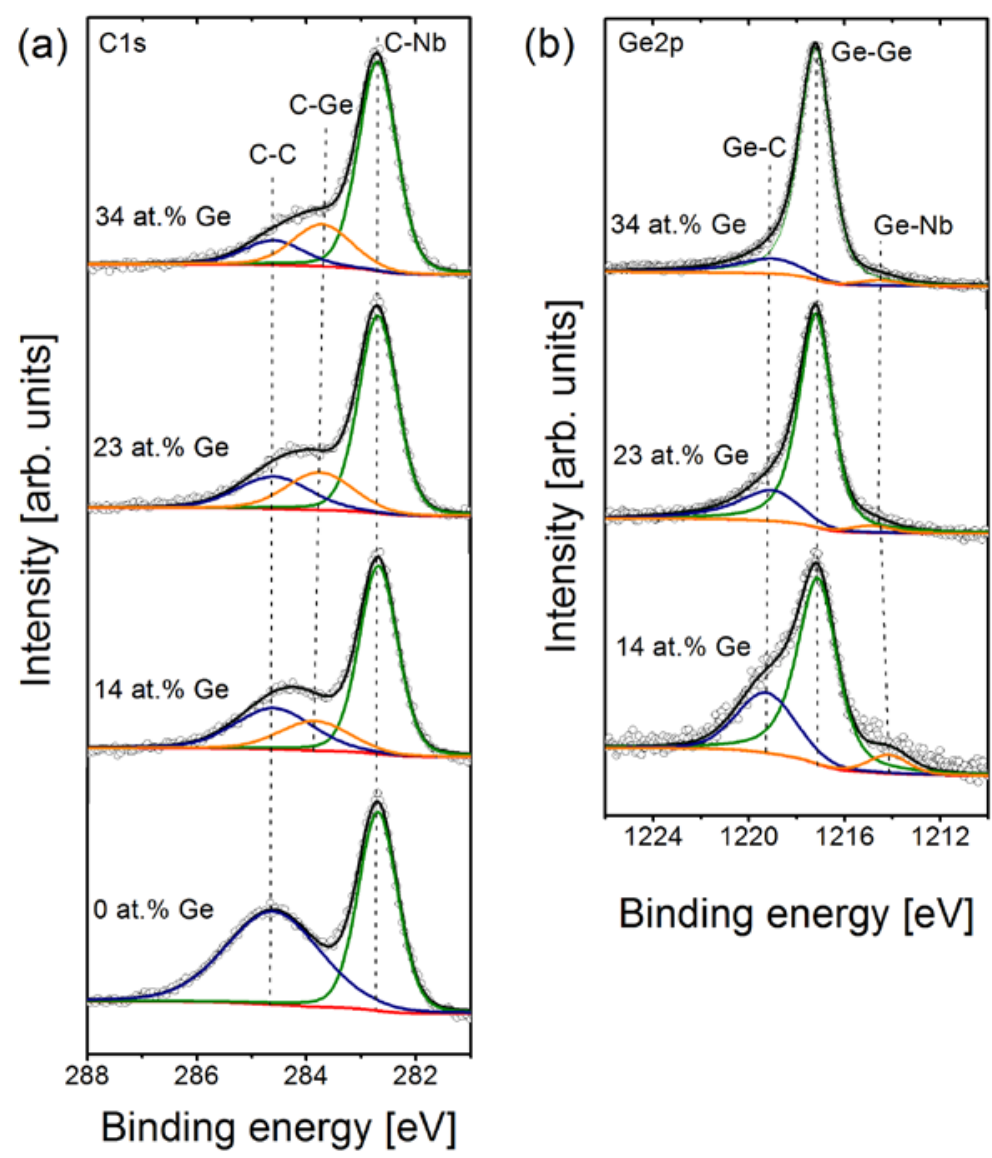

Binding energy $[\mathrm{eV}]$

Figure 3. (Color online) XPS measurements of (a) C1s and (b) Ge2p3/2 peaks for the films in series S1 
(a)

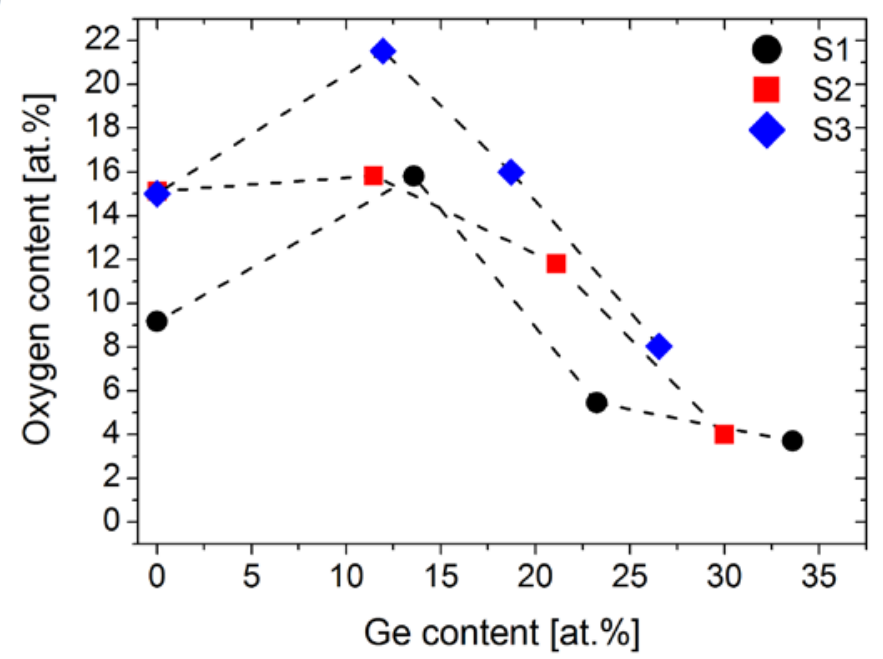

(b)

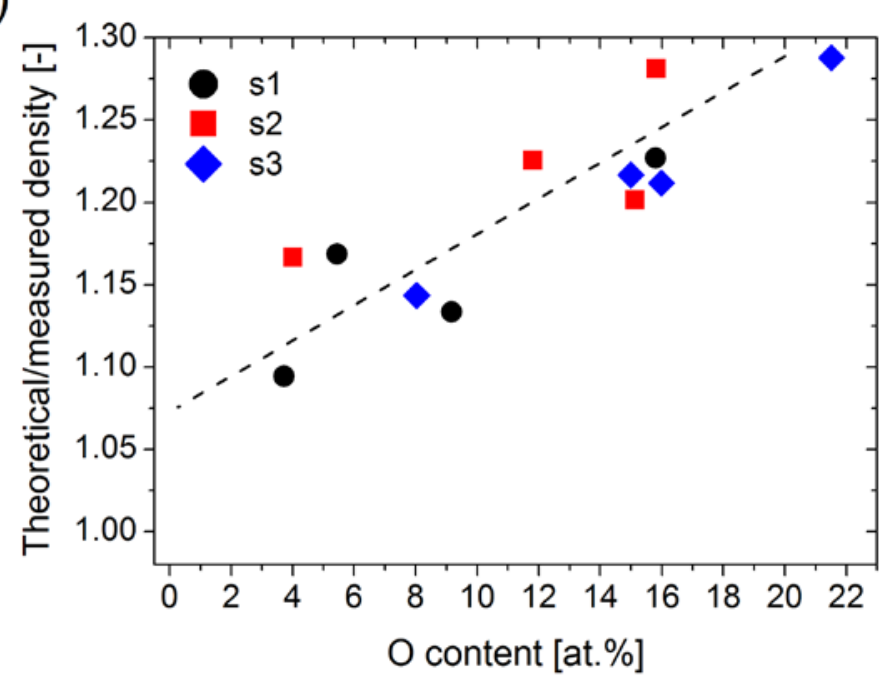

Figure 4. (Color online) (a) Measured O content in films as determined by XPS (b) Ratio between calculated and measured density for the films 


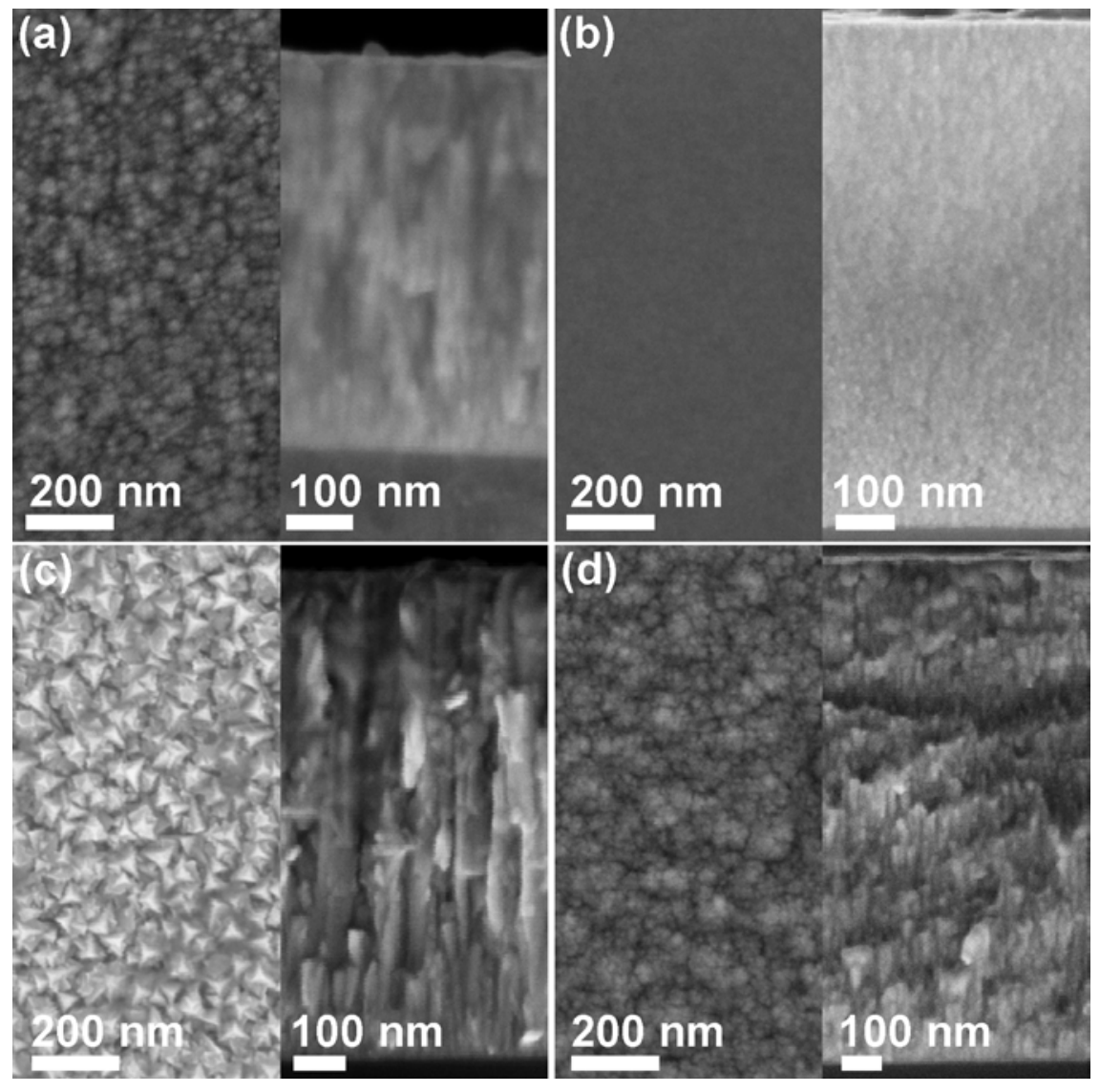

Figure 5. Cross sectional and top view SEM. (a) S1 0 at.\% Ge, (b) S1 34 at.\% Ge, (c) S3 0 at.\% Ge and (d) S3 27 at.\% Ge. 

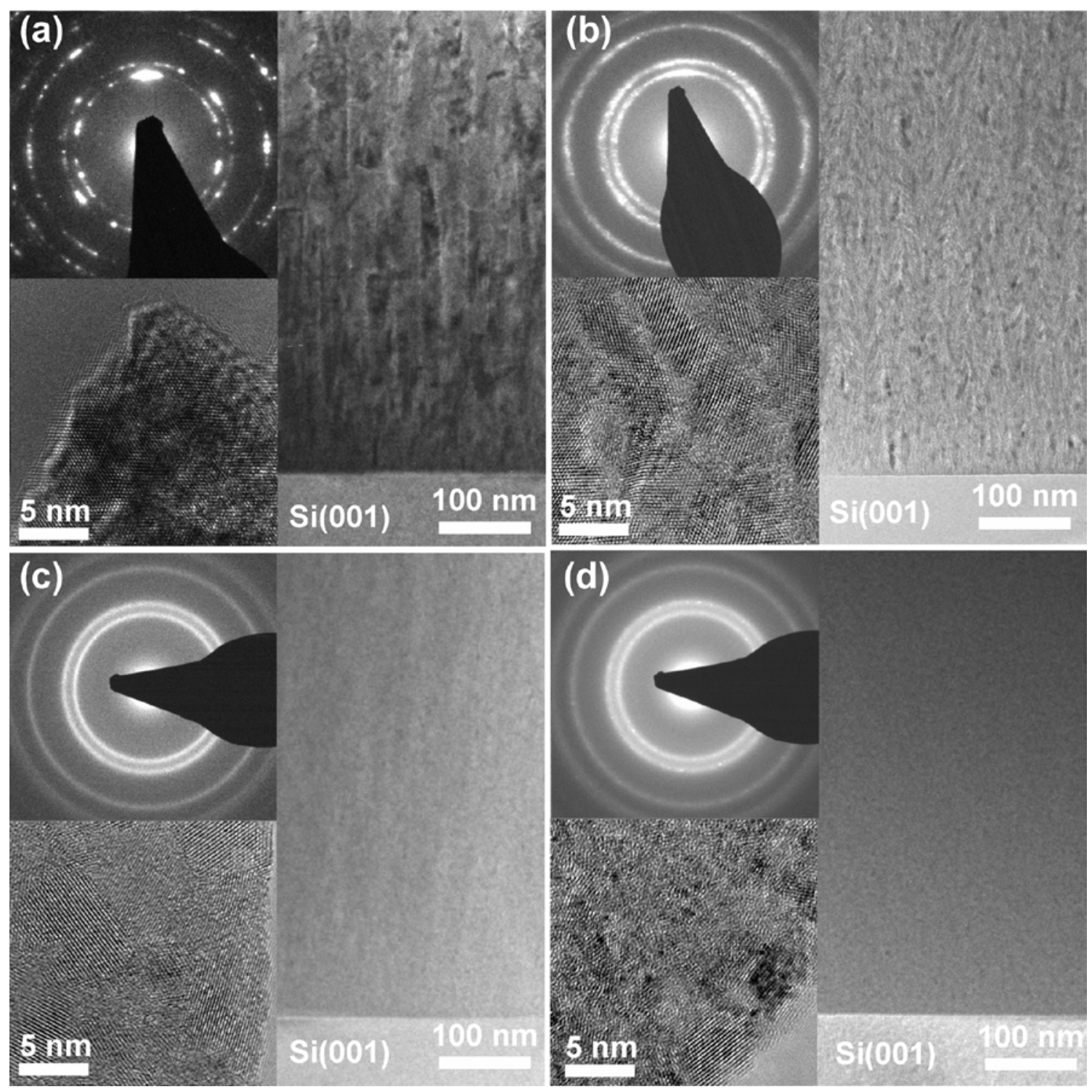

Figure 6. Cross sectional TEM with SAED and HRTEM insets. (a) S3 0 at.\% Ge, (b) S1 0 at.\% Ge, (c) S3 27 at.\% Ge and (d) S1 34 at.\% Ge. 


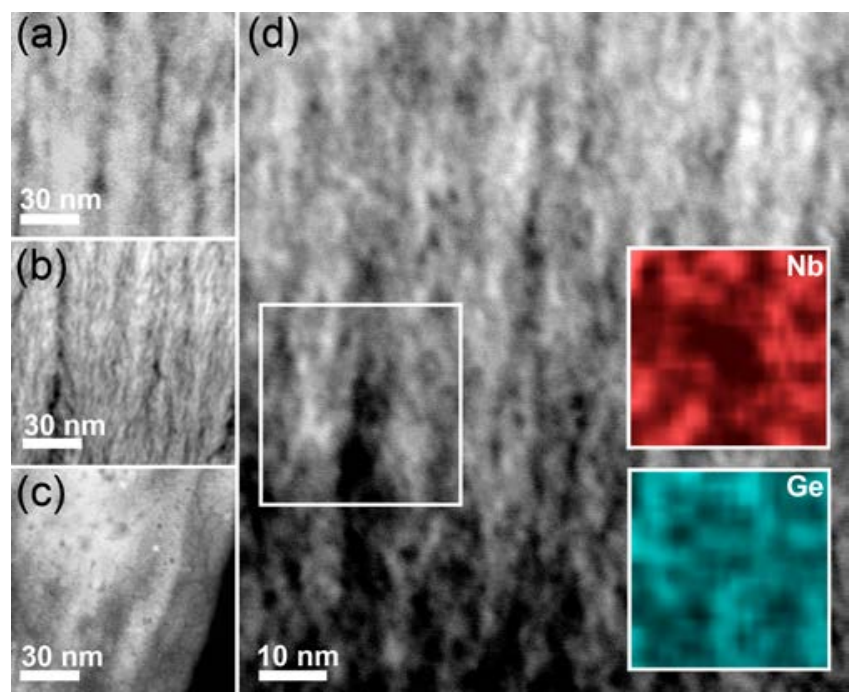

Figure 7. (Color online) STEM images of the structural evolution when adding Ge to the films. (a) and (b) show the binary samples from series S3 and S1, respectively. (c) shows a denser structure of an sample from S3 due to addition of 34 at.\% Ge. In (d) elemental maps of Ge and $\mathrm{Nb}$ for the series S1 sample with 14 at.\% Ge is presented.

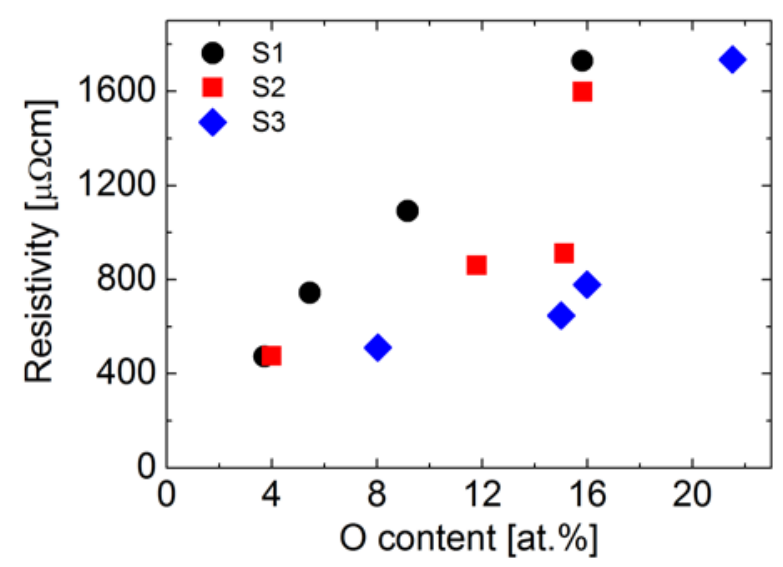

Figure 8. (Color online) Resistivity as a function of O content. 
a)

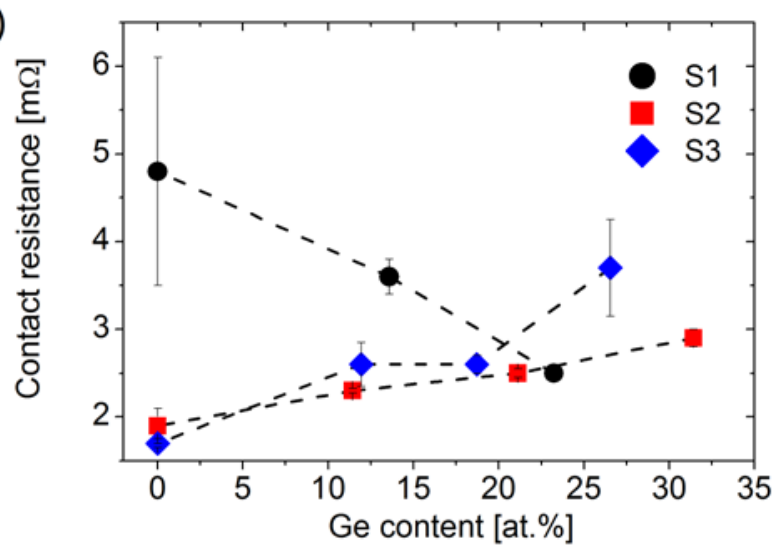

b)

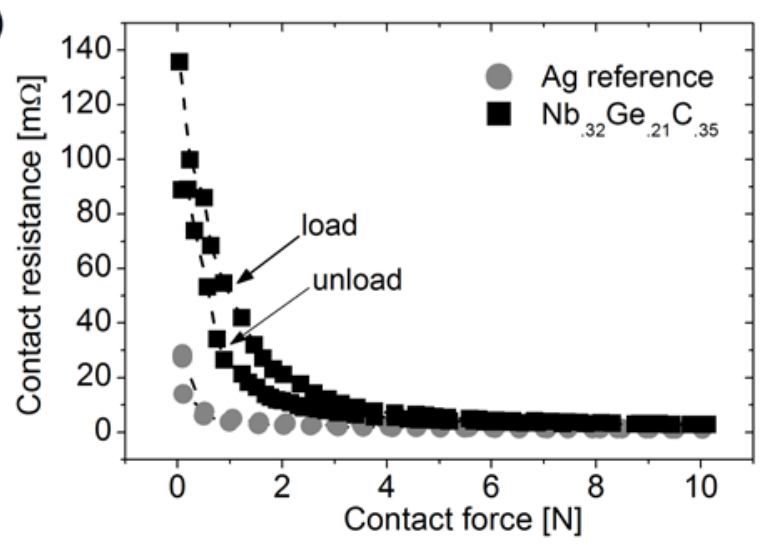

Figure 9. (Color online) (a) Contact resistance at $10 \mathrm{~N}$ for included films. (b) Typical load-unload curve. In (b) a Ag reference is added for comparison. 